\author{
V International Forum on Teacher Education
}

\title{
Pedagogical Components of Professional Activity of University Professors: Complex Analysis
}

\author{
E.V. Kovshikova * (a), I.V. Shindryaeva (b), E.V. Gulyaeva (c), A.A. Ogarkov (d) \\ (a), (b), (c), (d) Volgograd Institute of Management - Branch of the RANEPA under the RF President,Volgograd, \\ Russia
}

\begin{abstract}
Modern trends and qualification requirements to pedagogues in terms of the competency-based approach have foregrounded the issue of training of university professors. The article includes the analysis of pedagogical components of professional activity of university professors. The necessity of pedagogical training of professors without basic pedagogical education is substantiated. Theoretical analysis of numerous scientific papers provided the possibility to reflect views of scholars on this issue. In order to fulfill their mission, pedagogues need to be ready to solve professional pedagogical tasks, have a basic level of professional pedagogical competence. Diagnostic methods of research included: analysis of scientific publications and regulatory legal documents, as well as a questionnaire survey with the use of the application developed by Google Company, Google Forms. The resulting conclusions of the said research are used by the authors as exploratory research. The analysis of the results of the survey reveals that the majority of professors, irrespective of the length of their pedagogical activity, understand the necessity to constantly update their ideas about methods and technologies of training at university, introduce modern educational technologies into the training process and need the corresponding knowledge.
\end{abstract}

Keywords: competence approach, competence, education, pedagogical activity, university professor, pedagogical component.

(C) 2019 E.V. Kovshikova, I.V. Shindryaeva, E.V. Gulyaeva, A.A. Ogarkov.

This is an open access article distributed under the terms of the Creative Commons Attribution License (CC BY 4.0), which permits unrestricted use, distribution, and reproduction in any medium, provided the original author and source are credited.

Published by Kazan Federal University and peer-reviewed under responsibility of IFTE-2019 (V International Forum on Teacher Education)

\section{Introduction}


Pedagogical activity as a profession is traditionally associated in society with the process of development and education of children. Though a number of dictionaries construe pedagogy as a "science of upbringing of a Human Being", the calque of the concept of pedagogue traces its origin to the Greek "paidagogos - paidos child + ago I lead, bring up, which formed the concepts of tutor, teacher, instructor".

Consequently, there are some discrepancies in terms of practical application of pedagogy already at the level of dictionary entries: it is either work exclusively with a person of a "childhood" period or with a person of any age, including an "adulthood" period.

Back in the thirties of the nineteenth century, the German historian of pedagogy A.Kapp proposed the concept of "andragogy", which was introduced into scientific use. In 1989 Moring expresses a thought that, though the word "pedagogy" comes from the Greek word "pais", which means "child", nevertheless, since ancient times pedagogy has also meant "education" irrespective of the age of students (Draper, 1998). Andragogy comes from the word "aner" and means "an adult man" but not "an adult" of both sexes. In this regard, Moring proposes to use an English word to designate an adult but not the Greek one that is etymologically inaccurate. If the Greek language is preferred, then the Greek word "teleois", which means "adult", should be used. In this case, by analogy with pedagogical activity, a Human Being is followed due to education. Andragogy in the modern educational process of the higher school has prospects for development as both a field of social practice and an academic discipline, consequently, an area of scientific knowledge. Within the framework of this research, andragogy is considered as a part of classic pedagogy, specifically focused on educational processes with an audience of adults.

The close interrelationship of andragogy with pedagogy and theory of education of adults can be easily found during comparison of their subjects. The subject of pedagogy in a general form can be defined as development of person in a pedagogical reality. The subject of theory of education of adults is the system of education of adults as a social and cultural institution. Theory and methods of training of adult people in the context of lifelong learning is a specific subject of andragogy (Zmeev, 2007).

Despite the fact that in 1995 - 2000 pedagogical universities of Russia provided training in the specialty 031400 - andragogy, the corresponding departments were opened and educational programs were developed in the system of higher and continuing pedagogical education, the terms is hardly used in the system of administration of the higher school.

Organizational and administrative documents, for example, of the system of the RANEPA institutions of higher education contain the traditional concept "scientific and pedagogical activity of professors", "development activity of professors", "methodological activity of professors", though introduction of the very concept of andragogy into the content of university practice could foreground serious scientific and methodological issues on the peculiar features of professional knowledge that forms culture of informational and educational interaction of professors with adult people, first of all, students, including master students, participants of refresher courses.

In addition, the subject "Andragogy" at universities of non-pedagogical professional profile (for example, the system of training of managerial human resources in the RANEPA and other institutions) is relevant to those who are getting ready to become a university professor, an instructor in an institution of advanced training; those who are going to be involved in social work, educational activity, management, work in the mass media. In other words, activity of state and municipal employees (including social workers, PR specialists and others), politicians, commercial managers and many others relating to professions of a "person to person" type also includes an andragogical component, consequently, requires a particular special training. 
In particular, attracting the best graduates of the specialized faculties to the positions of teaching assistants of departments is a common practice to form the teaching staff potential of universities. In the future young instructors, developing their professionalism in the scientific field through participation in scientific events (conferences, forums, seminars, etc.), postgraduate studies with the subsequent defense of the dissertation research and assignment of academic degrees, are "grown" as scientists. Their teaching, pedagogical professionalism, despite availability of a number of pedagogical disciplines in the master's program, develops mainly through the practice of their own classroom work, which, besides accumulating the positive experience, often preserves accumulated pedagogical stereotypes and mistakes.

It is obvious that an adult person as a subject of the educational process or other business statusbased relationships is the field of intersection of scientific interests for the said areas of knowledge.

Thus, andragogue, first of all, is a pedagogue, an instructor the main professional function of whom is adult training. However, the andragogical (educational and development) function can and has to be assumed by any specialist working in the "person to person" system. It can be mastered on an optional or regulatory basis in the system of lifelong professional learning or continuing pedagogical education.

Andragogy, considering education in the context of human life, taking into account theoretical and methodological approaches, forms general and professional knowledge of students and helps them to master achievements of culture, to set their moral compass.

The complexity of the tasks of andragogy as pedagogy for adults in the system of higher education can be illustrated by the need to form the system of competences of specialists, university graduates (Kozyreva \& Radionovoy, 2004). It is the competency-based approach to education in the higher school that is today essential to the efficiency of functioning of universities as educational institutions.

In particular, the system of the RANEPA institutions of higher education train staff also for regulatory and administrative authorities, i.e., future state and municipal employees. State service institutions make systematic efforts to analyze complexes of competencies of their workers, state civil employees. A number of subjects of the Russian Federation (Vologda Region, Vladimir Region, Murmansk Region and other regions) develop or have already developed competency-based models of state civil employees focused on the management processes in terms of digital economy.

Creation of such models will sooner or later lead to correction of educational programs and change of the methods of training of such specialists. It is problematic to implement such changes without highly professional university pedagogues.

The concept of competence is used as a unit of measurement of professionalism of employees as one of the key units. Competence is interpreted as an integral personal characteristic reflecting the ability and willingness of a specialist to perform professional functions in compliance with the regulations and standards adopted for the time being. Therefore, the concept has a specific historical nature. The foundation of formation of the professional competence includes basic professional education, though, being dynamic, it manifests itself and can be assessed mainly in the course of practical activity, and its level can increase or decrease continuously throughout the entire professional life.

With the use of testing tools, it is also possible to measure the levels of competence formation: its qualitative states characterized by the degree of development of an employee's ability to act effectively when performing a set of official duties. Such complex tasks can not be solved intuitively by trained instructors of the higher school.

For example, the foundation of the formed competency-based model of state employee includes understanding of the essence of the performed management tasks and their complex connection with the 
tasks performed by other employees. Consequently, in terms of today's management crisis, its levels can be characterized as pre-professional (or amateur), based on earthy common sense and casual consciousness; empirical, the understanding of the matter formed in the course of everyday practical experience, usually tending towards primitive pragmatism and characterized by conservatism; theoretical, the understanding developed in the course of mastering knowledge from the relevant branches of science; methodological, that allows arranging an own conceptual way in the profession based on its thorough understanding, achieved as a result of integration of theoretical knowledge and practical experience (Pestereva, Tsvetlyuk, \& Nadeina, 2014).

It is obvious that specialists, managers with formed competencies of the higher, theoretical level can be trained only by instructors-pedagogues of the same, theoretical, level.

In addition to the elements of conceptual and legal analysis, it appears relevant to refer to organizational and functional aspects of activity of university professors and analyze them focusing on the pedagogical component of professional activity of university professors reflected in organizational and administrative documents. Job descriptions of professors of Volgograd Institute of Management of the RANEPA (positions of associate professor and assistant professor) were used to achieve this goal.

The interpretative analysis of the said documents showed that documents for the said positions of university professors are developed in compliance with the professional standard "Pedagogue in Professional Training, Professional Education and Continuing Professional Education". The positions are attributed to the category "Pedagogical Workers".

In terms of requirements for education and training, there are requirements for experience in research and pedagogical work, absence of restrictions on pedagogical activity established by the legislation of the Russian Federation.

In terms of necessary skills, there are requirements to use pedagogically sound forms, methods and techniques of work with students.

There is a documented requirement to use pedagogically sound forms, methods, ways and techniques to organize control and evaluation of progress in training courses, comply with standards of pedagogical ethics, establish pedagogically reasonable relations with students, etc.

The descriptions also contain requirements in the field of professional knowledge of university professors. They are knowledge of psychological and pedagogical foundations of teaching; age peculiarities of students; pedagogical, psychological and methodological foundations of development of students' motivation in classes of various types.

Therefore, it is possible to conclude that in the said documents there are no direct requirements for availability of pedagogical education of professors, but there are requirements for pedagogical experience, i.e., experience in pedagogical activity. Nevertheless, attention should be paid to the fact that pedagogical training is necessary also for university professors who have some pedagogical experience without any pedagogical education (Kosyakin, 2008). They also formulate requirements for professional knowledge of university professors in the area of psychology and pedagogy with consideration of age peculiarities of students and methods of educational process, including control of progress in academic disciplines, but direct requirements for development work of professors are not formulated.

It is difficult to gain the above-mentioned knowledge and skills independently, without mastering special disciplines within pedagogical education focused on pedagogical activity at universities 


\section{Problem Statement}

Professional activity of modern university professors includes many components. Based on annual individual planning and reporting documents, it consists of scientific, methodological, development, educational and a range of other types of work. All of them require special professional education, however, first of all, the issue of the obligatoriness of pedagogical education for university professors is discussed in the university environment, because educational, development and methodological types of work form pedagogical components of their professional activity.

We focus our attention on the university educational process the efficiency of which directly depends on the professional knowledge of professors about the subject of impact, an adult person.

The scientific context of andragogical knowledge is identified through consideration of the following categories (Kopylova, 2013):

1) person (at the stage of life characterized as adulthood);

2) adulthood (the feature that establishes the age and social range for consideration of peculiarities of an adult person as a subject of training);

3) education (social and cultural mechanism of purposeful development and formation of a human feature (image) on the basis of training and upbringing organized in relation to the content and the process);

4) education of adults (the process of professional and personal development of people implemented in variable forms in the context of lifelong learning);

5) lifelong learning (education considered in relation to the holistic space of human life).

In order to increase efficiency of the educational process, modern university professors need knowledge in the area of sociological data on the state of adult education, trends in development of the field of adult education); knowledge in the area of psychology of adult people at different stages of life (Trubilin \& Grigorash, 2011); skills of studying the values that determine the content and methods of education of various categories of population (Shindryaeva, 2018).

The field of education, like any other branch of national economy, can function normally if it is provided with trained staff of specialists (Mkrtchyan, 2015).

The modern social and economic situation in Russia predetermines a steady increase in the importance of education of adult population in the coming decades. In terms of the absolute aging of the Russian population, the percentage of adults who need continuing, professional and general cultural training is constantly increasing.

This circumstance makes modern university pedagogy, defined by us as intuitive, completely insufficient. To improve the efficiency of the educational process at university, professors need to rely upon theoretically fixed knowledge not just in the field of social and psychological or professional interaction of adult people but, first of all, in cases where work with a certain content to be mastered is required, and where adult people face educational tasks.

The duty of professors of any disciplines is to teach students and participants to think actively, to form their ability to find knowledge themselves.

Knowledge is firm only when it is "acquired" by the efforts of one's thought rather than just by memory. This is a peculiarity of the cognitive process. It is established experimentally that under equal conditions only $10 \%$ of what people hear, up to $50 \%$ of what they see, $90 \%$ of what they do is impressed on their memory, as noted by Kovalenko \& Shishkina (2015) 


\section{Research Questions}

Are university professors pedagogues in a traditional sense of this term, or their pedagogical activity has particular peculiar features? Which areas of professional activity of professors are pedagogical, and which special knowledge is necessary for their implementation? These issues are relevant for personnel work with university professors, in particular, from the point of view of their education and professional suitability.

From a legal point of view (No. 273-FZ), "pedagogical worker is an individual who is in a labor, employer-employee relationship with an organization carrying out educational activity and performs duties to teach, develop students and (or) organize educational activity", and "student is an individual who masters an educational program".

Therefore, in the concepts of pedagogical worker, educational organization and student, the term system of the federal law does not reflect age periods of the person in relation to whom pedagogical activity is carried out.

On the other hand, the federal legislation (No. 350-FZ) stipulates early grant of insurance pension to "persons who carried out pedagogical activity in institutions for children for at least 25 years regardless of their age".

In other words, the law does not stipulate this procedure for university professors (whose work experience is evaluated as instruction, specifically pedagogical, because not children are trained at university), which questions the classic pedagogical component of their professional activity in training of future specialists with higher education

\section{Purpose of the Study}

To analyze the pedagogical components of the professional activity of the University teacher, to determine the qualification requirements for the teacher in modern conditions, to justify the need for pedagogical training of teachers who do not have basic pedagogical education.

\section{Research Methods}

Content analysis of scientific publications and regulatory legal documents and online questioning $(\mathrm{N}=42)$. The respondents included university professors in Volgograd, up to 40 years old, without basic pedagogical education. The type of sampling is quota, the margin of sampling error does not exceed 5\%. It appears relevant to study the opinion of university professors about the pedagogical component of their professional activity, in order to find out their professional position on the issue of availability of specific pedagogy (andragogy) components in their educational activity and the sources of its formation.

\section{Findings}

The results of the questioning show that two thirds of the respondent professors consider scientific activity of professors leading in comparison with educational one, performance of which is attributed by them to related types of works. In addition, $8.3 \%$ narrow down educational activity of university professors 
to transmission of scientific knowledge to any members of the audience. Just a quarter of the survey participants think that educational work, according to the structure of hourly workload and the reporting system, is the main type of work of university professors.

Therefore, three quarters of the survey participants, considering the educational process as secondary in their professional activity, potentially will not focus their efforts on improving its efficiency and try to develop their competencies in the area of pedagogic activity. This situation appears problematic to us and requires correction.

Comparing educational activity of university professors with the same type of activity of school teachers, the respondent professors in half of the cases thought they were identical in goals and objectives, the other half of the respondents saw differences in both the goals and objectives of school teachers and university pedagogues and in the forms and methods of their implementation.

The answers confirmed that a significant part of university professors applies school pedagogy to the educational process at universities and have a generalized view of its goals, objectives, forms and methods.

In addition, all the respondents agreed that educational work as part of professional activity of university professors requires of them special theoretical (scientific and practical) knowledge.

The answers indicate that practice make them face the problems settlement of which required theoretical knowledge in the area of educational process.

Regarding the question about the position of development work in the professional activity of university professors, one third of the respondents considered it an integral part of the professional activity of university professors. Moreover, one quarter of the respondents correlate development work only with the process of training of underage first-year students, almost half of the survey participants (41.7\%) considered it possible to develop both underage first-year students and adult students (bachelor and master students) during the training process, and none of the respondents considered it possible to carry out development work in the audience of adult participants of professional retraining.

These answers indicate quite approximate knowledge of the respondents about development, the young university adults and adult participants of retraining at universities.

Comparing development work of university professors with the same type of activity of school teachers, a little less than half of the respondent professors (41.7\%) considered them to be identical in goals and objectives, while the rest $(58.3 \%)$ did not see similarities in the development processes of universities and schools.

These answers, which divided the respondents almost equally, speak to the fact that there are serious lacunae in the field of knowledge of university professors about development of adults. Consequently, almost all the respondents (97.3\%) stated that development work as a part of professional activity of university professors required of them special theoretical knowledge.

Analyzing methodological work in the professional activity of university professors, about half of the respondents attributed it to a formal type of works, while one third of the participant answered that such work was carried out both in classrooms with students and during development of personal academic and methodological materials. However, $91.7 \%$ of professors believe that methodological work as part of professional activity, from their point of view, requires of university professors special theoretical (scientific and practical) knowledge.

Answering the questions about scientific work as part of professional activity of university professors, $83.3 \%$ of the respondents stated that it was equally important, as well as pedagogical activity of 
university professors, which is evidenced by both the structure of payment for professors' labor and labor costs and time expenditures for its implementation.

More than half of the respondents attributed professional activity of university professors to pedagogic in essence, which, in their opinion, requires of them compulsory special professional training completed in an educational institution. In addition, one third of the respondents called such training preferable, suggested that it could be completed independently in terms of self-education, since pedagogical professional activity of university professors was not the main one. $8.3 \%$ of the respondents did not attribute professional activity of university professors to pedagogical but deemed it, first of all, scientific, which, in their opinion, did not require special pedagogical training completed in an educational institution.

Thus, the obtained results led us to a number of conclusions.

A vast majority of professors of today's universities consider the educational process in their professional activity as secondary in relation to their scientific activity. This is facilitated also by the organizational culture of the modern higher school and the structure of payment for professors' labor focused on academic degrees and ranks.

The majority of professors do not see a considerable difference between pedagogical processes at universities and at schools, which makes it impossible for them to take into account specific characteristics of adult students, including master students, as well as participants in the educational process of universities.

The absolute majority of university professors, relying upon their practical experience, think that pedagogical activity of higher school professors requires of them special theoretical knowledge in the area of methods of training and development of adults participating in the educational process.

\section{Conclusion}

The requirements imposed on modern pedagogues and reflected in the Federal Law "On Education in the Russian Federation" do not imply division of pedagogues into those who have and those who do not have pedagogical education. Pedagogues, specialists that started working in educational organizations already at the first stage of their pedagogical activity, must have a qualification level that is sufficient for its performance. Pedagogical workers are not able to implement many of these requirements because they do not have special pedagogical knowledge and skills. Consequently, they will have to acquire pedagogical knowledge through the system of retraining and advanced training and due to selfeducation. In addition, the process of mastering pedagogical knowledge and forming professional pedagogical competencies should be considered as a process of professional retraining for persons without basic pedagogical education. It is actually their second professional training for getting basic professional pedagogical education. It is reasonable to organize advanced training of the university academic staff synchronously with the professional pedagogical activity taking into account the peculiar features of adult training (Glubokova, 2016).

Moreover, the pedagogical component in activity of university professors, from the point of view of the legal, conceptual, organizational and functional analysis is presented in the organizational and administrative documents of universities as dominant, which allows attributing them to the category of pedagogical workers. This fact foregrounds issues of obligatory special pedagogical education of 
university professors according to the programs intended for higher school pedagogy, which may be developed also in terms of pedagogy (training of minors at universities) and andragogy (training of adults at universities).

\section{Acknowledgments [if any]}

The work is written with the support of Volgograd Institute of Management - RANEPA, within the framework of research project No. 01-2018VIU 'Competency-Based Model of State Civil and Municipal Employee in the Context of Society Digitization (in Terms of Volgograd Region)'.

\section{References}

Draper, J. (1998). The metamorphoses of andragogy. Canadian journal for the study of adult education, 12(1), 3-26.

Glubokova, E. N. (2016). Variable models of advanced training of modern university professors. Izvestiya of the Herzen State Pedagogical University of Russia, (179), 553-61.

Kopylova, A. V. (2013) Implementation of the andragogical approach in the system of advanced training of pedagogues. Professional Education in Russia and Abroad, 3(11), 75-79.

Kosyakin, Yu. V. (2008). Practical prerequisites for the necessity and formation of the system of pedagogical training of scientific and pedagogical staff of university. Proceedings of the International Symposium on Reliability and Quality, 5(1), 184-188.

Kovalenko, O. G., \& Shishkina, N. A. (2015). Pedagogical activity of professors in teaching disciplines for university students. Young scientist (Molodoy uchenyi), (21), 790-792.

Kozyreva, V. A., Radionovoy, N. F. (2004). Kompetentnostny podkhod v pedagogicheskom obrazovanii: kollektivnaya monografiya. St. Petersburg, RGPU Publishing.

Mkrtchyan, E. R. (2015). The state and regional peculiarities of reproduction of scientific and pedagogical human resources in Russia: experience of sociological analysis. Scientific Bulletin of Volgograd Branch of the RANEPA. Series: Political Science and Sociolog, (3), 33-45.

Pestereva, N. M., Tsvetlyuk, L. S., \& Nadeina, O. S. (2014). Formation of professional competencies of state employees. Moscow: Publishing House of Moscow University for the Humanities.

Shindryaeva, I. V. (2018). Professional personal features of medical university professors as viewed by students (the experience of sociological research). Education. Science. Career Collection of scientific articles of the International Scientific and Methodological Conference. In 2 volumes. Managing Editor A.A. Gorokhov, 371-376.

Trubilin, A. I., \& Grigorash, O. V. (2011). System of quality evaluation of activity of staff and subfaculties of high school. Alma mater (Vestnik vysshei shkoly), 2, 60-64.

Zmeev, S. I. (2007). Andragogy: fundamentals of theory, history and technology of adult training. Moscow, PER SE. 